Revista Brasileira de Agricultura Irrigada v.11, nº.6, p. 1772 - 1783, 2017

ISSN 1982-7679 (On-line)

Fortaleza, CE, INOVAGRI - http://www.inovagri.org.br

DOI: $10.7127 /$ rbai.v11n600578

Protocolo 578.17 - 20/02/2017 Aprovado em 17/05/2017

\title{
CUSTO DA EROSÃO HÍDRICA PARA DIFERENTES USOS DO SOLO NO SEMIÁRIDO BRASILEIRO
}

\author{
José Wellington Canuto Lima ${ }^{1}$, Rinaldo dos Santos Araújo ${ }^{2}$, Helba Araújo de Queiroz \\ Palácio ${ }^{3}$, José Ribeiro de Araújo Neto ${ }^{4}$, Julio Cezar Neves dos Santos ${ }^{5}$
}

\begin{abstract}
RESUMO
Objetivou-se, com o presente estudo, avaliar as perdas de água, solo e íons $\left(\mathrm{PO}_{4}^{3-}, \mathrm{K}^{+}\right.$, e $\mathrm{Ca}^{2+}$ $+\mathrm{Mg}^{2+}$ ) pela ação do escoamento superficial direto, bem como determinar os custos econômicos associados às perdas em diferentes usos do solo. O monitoramento foi realizado em área experimental na região semiárida do Estado do Ceará, em três parcelas de erosão de $20 \mathrm{~m}^{2}$, sob condições de chuva natural e diferentes tipos de uso do solo: vegetação de caatinga conservada (CC), desmatamento/queima/cultivo de pastagem (DQP) e desmatamento/queima sem vegetação (DQSV). O período de avaliação corresponde às estações chuvosas de 2013 e 2014, as quais apresentaram precipitações de 630,75 e 742,89 mm, respectivamente. As coletas de escoamento foram realizadas a cada evento de chuva erosiva. As perdas de íons solúveis e trocáveis foram avaliadas e, em seguida, os custos com adubos para repor as perdas em cada uso do solo foram calculados. Após fazer uma média dos custos com perdas por erosão para os dois anos, observou-se que o manejo (DQSV) apresentou as maiores perdas financeiras (R\$ 118,96 ou US\$ 33,25) por hectare e por ano. Já as menores perdas por erosão foram proporcionadas pela parcela de CC com R\$ 1,94 (US\$ 0,54) por hectare e por ano.
\end{abstract}

Palavras-chave: Manejo do solo. Escoamento superficial. Impacto financeiro.

${ }^{1}$ Licenciado em Pedagogia. Mestre em Gestão Ambiental. Técnico Administrativo do Instituto Federal do Ceará Campus Iguatu. Rodovia Iguatu Varzea Alegre $\mathrm{km} \mathrm{5,} \mathrm{Vila} \mathrm{Cajazeiras.} \mathrm{Iguatu} \mathrm{-} \mathrm{CE.}$ wellingtoncanutoifce@gmail.com

${ }^{2}$ Doutor em Química. Mestre em Engenharia Química. Professor do Instituto Federal do Ceará Campus Fortaleza. Avenida 13 de maio, 2081, rinaldoifce@gmail.com

${ }^{3}$ Licenciada em Ciências Agrárias. Doutora em Engenharia Agrícola. Mestrado em Irrigação e Drenagem. Professora do Instituto Federal do Ceará Campus Iguatu. Rodovia Iguatu Varzea Alegre, km 5, Vila Cajazeiras. Iguatu-CE. helbaraujo23@yahoo.com.br

${ }^{4}$ Graduado em Tecnologia de Irrigação e Drenagem. Mestre em Engenharia Agrícola. Doutorando em Engenharia Agrícola pela Universidade Federal do Ceará. Técnico Adoministrativo do Instituto Federal do Ceará Campus Iguatu. . Rodovia Iguatu Varzea Alegre, $\mathrm{km} \mathrm{5,} \mathrm{Vila} \mathrm{Cajazeiras.} \mathrm{Iguatu} \mathrm{-} \mathrm{CE.}$ juniorifcelabas@gmail.com

${ }^{5}$ Graduado em Tecnologia de Irrigação e Drenagem. Mestre em Engenharia Agrícola. Doutorando em Engenharia Agrícola pela Universidade Federal do Ceará. Professor efetivo do Instituto Federal do Triângulo Mineiro, Campus Uberlândia. Faz. sobradinho, s/n, cx postal-592 rural - Uberlândia, MG . juliosantos@iftm.edu.br 


\title{
COST OF WATER EROSION FOR DIFFERENT LAND USES IN THE BRAZILIAN SEMIARID TROPICAL
}

\begin{abstract}
The aim of the present study was to evaluate the losses of water, soil and ions $\left(\mathrm{PO}_{4}^{3-}, \mathrm{K}^{+}\right.$, e $\mathrm{Ca}^{2+}+\mathrm{Mg}^{2+}$ ) by the action of direct superficial runoff, as well as to determine the economic costs associated with the losses in different uses of soil. The monitoring was conducted in the experimental area in the semi-arid region of the Ceará State, in three installments of erosion of $20 \mathrm{~m}^{2}$ under natural rainfall conditions and in different types of soil use: vegetation of Conserved Caatinga (CC), deforestation/burning/pasturage cultivation (DBP) and deforestation/burning without vegetation (DBW/OV). The evaluation period corresponds to the rainy seasons of 2013 and 2014, which presented precipitations of 630.75 and $742.89 \mathrm{~mm}$, respectively. The flow collects were performed at each erosive rainfall event. The losses of soluble and exchangeable ions were evaluated and then the fertilizer costs to replace losses in each use of soil were calculated. After making an average of the costs of erosion losses for the two years, it was observed that the management (DBW/OV) presented the largest financial losses (R\$ 118.96 or US\$ 33.25) per hectare and per year. Already the smallest losses by erosion were afforded by the CC parcel of R 1.94 (US\$ 0.54) per hectare and per year.
\end{abstract}

Keywords: Soil management. Superficial flow. Financial impact.

\section{INTRODUÇÃO}

O uso e ocupação do solo têm gerado grandes impactos ambientais. Dentre os problemas que muito tem contribuído para esta degradação destacam-se o desmatamento, as queimadas, a monocultura e a criação desordenada de animais (BERTOL et al., 2011). Segundo Palácio et al. (2013), as práticas da agricultura tradicional têm causado aos ecossistemas do semiárido vultosas perdas em seus recursos naturais. Estes autores citam ainda que técnicas de manejo da vegetação que busquem uma exploração sustentável, seja para produção de alimentos, pastagem ou atividade madeireira, ainda são pouco estudadas, conhecida ou adotada no semiárido brasileiro.

O desmatamento e a queima também contribuem para a redução da infiltração, aumentam o escoamento superficial e potencializam a erosão hídrica, tornando os solos pobres em nutrientes e em matéria orgânica, contribuem para o assoreamento dos rios, enchentes e eutrofização das águas de reservatórios superficiais (GUAN-HUA et al., 2011; BERTOL et al., 2011).
Segundo Moruzzi et al. (2009), para o entendimento dos processos erosivos é imprescindível avaliar a infiltração e o escoamento da água durante e após os eventos chuvosos. A cobertura vegetal é outro fator importante que influencia na redução do escoamento superficial e consequentemente nas perdas de água e solo (CAVALCANTI et al., 2012; GARCIA-ESTRINGANA et al., 2013; RODRIGUES et al., 2013). Porém, segundo González-Hidalgo et al. (2013) o transporte de sedimentos em pequenas microbacias é mais dependente de eventos extremos do que em bacias maiores, onde os efeitos das conectividades são mais complexos.

Em eventos de escoamento superficial, os nutrientes existentes no solo, especialmente na camada superficial, são transportados pela água causando o empobrecimento do solo (BERTOL et al., 2011). Este arraste é influenciado pelo manejo e preparo do solo, como: aração, gradagem, e pela intensidade das chuvas. Além do que, estes nutrientes vêm se tornando uma das maiores fontes de poluição dos reservatórios de águas superficiais e subterrâneas 
(BARBOSA et al., 2009; OLIVEIRA et al., 2012; LIU et al., 2014).

As perdas de nutrientes dos solos proporcionadas por diferentes manejos e por processos de erosão hídrica, quando correlacionadas às quantidades de adubos utilizadas para reposição da fertilidade do solo, podem alcançar cifras entre US\$23.00 a US\$ 24.94 ha $^{-1}$ ano $^{-1}$. Quando se associa os prejuízos com a produção, levando em consideração os custos com transporte, mão de obra, utensílios e máquinas, estas perdas podem alcançar valores entre US\$ 77 a US\$ 146 ha $^{-1}$ ano $^{-1}$ (PIMENTEL et al., 1995; BERTOL et al., 2007; CARVALHO et al., 2014). Além das perdas financeiras, a perda de solo e os elementos que lhe estão associados podem causar sérios problemas ambientais, como o assoreamento e a eutrofização dos corpos hídricos além de prejuízo econômico ao produtor e à sociedade (CARDOSO et al., 2012; PEREIRA et al., 2013).

A utilização de práticas conservacionistas tem sido apresentada como uma opção para assegurar a sustentabilidade do uso agrícola dos solos (ANDRADE et al.,
2009). Com a adoção dessas práticas pode-se assegurar menores perdas de solo e nutrientes devido principalmente em decorrência da manutenção da cobertura vegetal, seja em sistema agroflorestais ou com manejo da cobertura do solo (THOMAZINI et al., 2012; CARDOSO et al., 2012).

Neste contexto, objetivou-se com o presente estudo avaliar as perdas de água, solo e íons $\left(\mathrm{PO}_{4}{ }^{3-}, \mathrm{K}^{+}, \mathrm{Ca}^{2+}\right.$ e $\left.\mathrm{Mg}^{2+}\right)$ agregados aos sedimentos e carreados pela água de escoamento superficial, bem como determinar os custos econômicos associados às perdas, no semiárido brasileiro.

\section{MATERIAL E MÉTODOS}

A área de estudo está localizada no semiárido cearense, na bacia hidrográfica do Alto Jaguaribe no município de Iguatu, Ceará, Brasil (Figura 1), em uma área experimental pertence ao Instituto Federal do Ceará (IFCE) - Campus Iguatu. Ela fica situada entre as coordenadas geográficas de $6^{\circ} 23^{\prime} 36^{\prime \prime}$ ' a

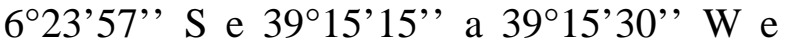
altitude média de $217,8 \mathrm{~m}$.

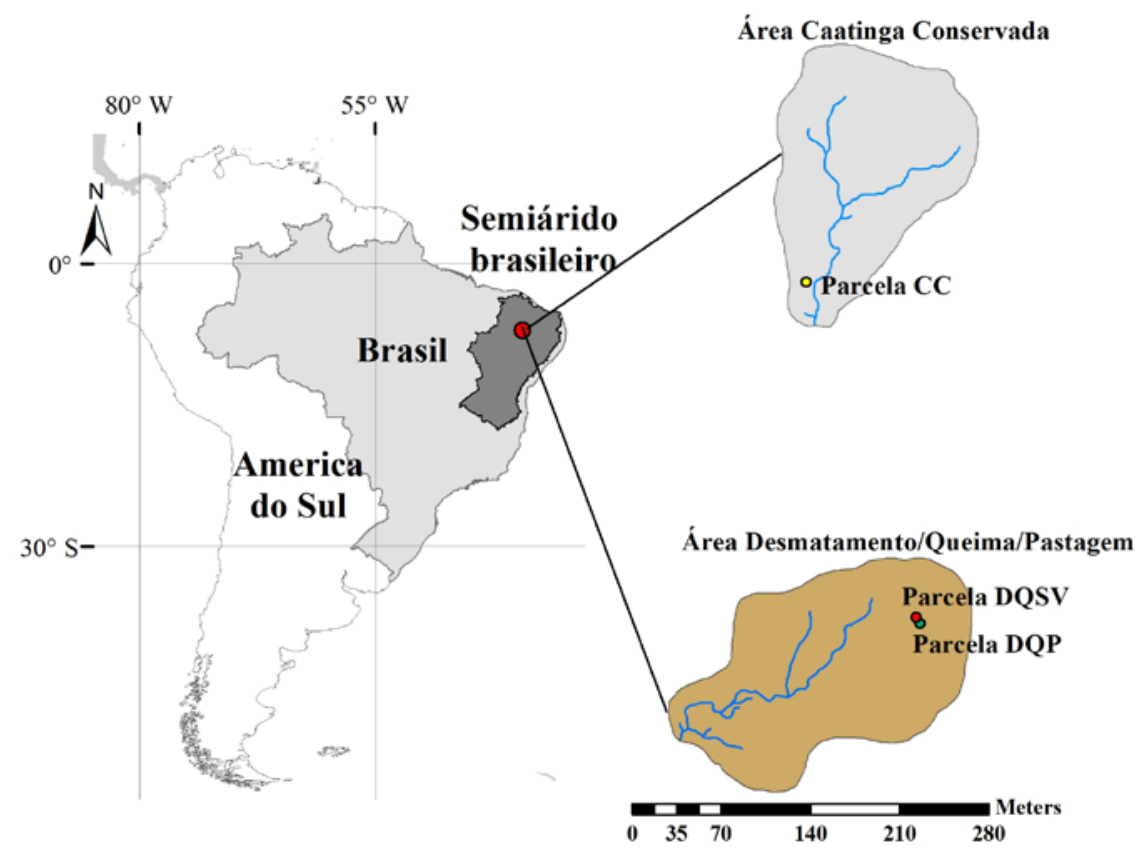

Figura 1 - Localização da área de estudo no semiárido do Brasil.

O clima da região é do tipo BSh' (Semiárido quente), de acordo com a classificação climática de Köppen, com temperatura média sempre superior a $18{ }^{\circ} \mathrm{C}$ no 
mês mais frio. O Índice de Aridez elaborado por Thornthwaite é de 0,44, ou seja, semiárido. A evapotranspiração potencial média no município de Iguatu é de $1.988 \mathrm{~mm}$ $a^{-1}$ e a precipitação média histórica é de 864 mm (AGRIEMPO, 2013). A distribuição temporal das chuvas apresenta uma concentração de $85 \%$ no período de janeiromaio, dos quais cerca de 30\% são registrados no mês de março.

O solo da área experimental é classificado como Vertissolo Ebânico Carbonático Típico (EMBRAPA, 2013), através de abertura de duas trincheiras na área experimental. O relevo é suave ondulado, os solos são relativamente profundos (2 a $3 \mathrm{~m}$ ) com presença elevada de silte (39\%) e argila (32\%) nas camadas superficiais e subsuperficiais. Devido ao tipo de argila (2:1 / montmorillonitae) presente no solo da área, é comum o surgimento de rachaduras na superfície na época de estiagem.

As coletas de dados, para mensuração das variáveis relacionadas à precipitação, perdas de água, solo e nutrientes, foram realizadas durante as estações chuvosas (janeiro a junho) dos anos de 2013 e 2014. Os dados de precipitação foram obtidos em estação meteorológica instalada na própria área de estudo. Para mensuração das perdas de solo, água e íons dissolvidos foram instaladas três parcelas de erosão com área de $20 \mathrm{~m}^{2}(2 \times 10 \mathrm{~m})$ e comprimento maior obedecendo o sentido da declividade do terreno (Figura 2). A primeira parcela de erosão, com declividade de 7,7\%, foi mantida com cobertura de Caatinga conservada (CC) estando em regeneração há mais de trinta anos. A segunda parcela de erosão, com declividade de 8,8\%, é representativa do manejo de desmatamento da Caatinga, seguido de queima e cultivo de capim forrageiro (Andropogon gayanus Kunt) para pastagem (DQP). Na terceira parcela de erosão, com declividade de $8,4 \%$, o manejo foi de desmatamento da Caatinga, seguido de queima e o solo foi mantido exposto durante todo o experimento (DQPSV), de forma a representar os processos erosivos sem o efeito protetor e dissipador de energia fornecidos pelas coberturas vegetais.
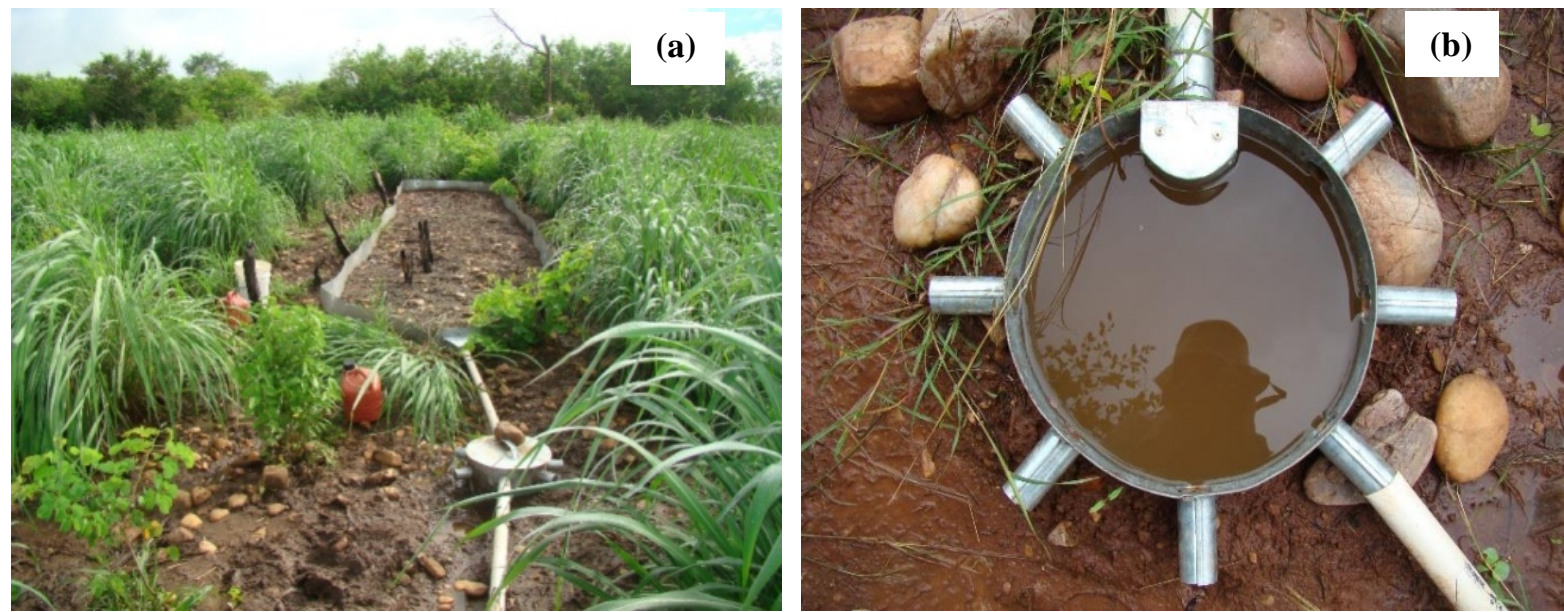

Figura 2 - (a) Parcela de erosão e (b) sistema coletor de escoamento da parcela de erosão.

Para a quantificação das perdas de água, solo e íons dissolvidos foram realizadas coletas, após cada evento de chuva erosiva no acumulado de 24 horas, usando tanques coletores instalados na extremidade inferior de cada parcela de erosão (Figuras 2b). Nestas mesmas amostras foram quantificadas as perdas de solo por meio da determinação dos sólidos suspensos (SS) e íons dissolvidos por meio da determinação individual de cada elemento.

Para avaliar as perdas dos íons solúveis foram quantificadas, nas amostras de água de escoamento coletadas nas parcelas de erosão, as concentrações dos parâmetros químicos: cálcio $\left(\mathrm{Ca}^{2+}\right)$, magnésio $\left(\mathrm{Mg}^{2+}\right)$; fosfato $\left(\mathrm{PO}_{4}{ }^{3-}\right.$ ) e potássio $\left(\mathrm{K}^{+}\right)$todos conforme a metodologia descrita por Silva (2009). Em 
seguida, sabendo os valores das perdas de água por cada evento gerador de escoamento (L) e as concentrações de cada íon solúvel ( $\mathrm{mg} \mathrm{L}^{-1}$ ) foram calculadas as perdas de cada nutriente $\left(\mathrm{Kg} \mathrm{ha}^{-1}\right)$.

Foram realizadas análises químicas de amostras de solo da camada superficial do solo (0 a $20 \mathrm{~cm})$ nas proximidades das parcelas de erosão, coletadas ao final da estação chuvosa dos anos de 2012 e 2013 (Tabela 1), para utilizar o teor dos íons presentes no solo como base para os cálculos das perdas trocáveis de nutrientes nos anos sucessores $2013 \quad$ e 2014.

Tabela 1 - Resultado da análise química dos parâmetros avaliados na camada superficial do solo (0 a $20 \mathrm{~cm})$.

\begin{tabular}{cccccc}
\hline \multirow{2}{*}{ Parâmetros } & \multirow{2}{*}{ Unidades } & \multicolumn{3}{c}{ CC } & \multicolumn{2}{c}{ DQP } \\
\cline { 3 - 5 } & & 2012 & 2013 & 2012 & 2013 \\
\hline $\mathrm{Ca}^{2+}$ & $\mathrm{mg} \mathrm{dm}^{-3}$ & 12,9 & 18,0 & 14,9 & 14,7 \\
$\mathrm{Mg}^{2+}$ & $\mathrm{mg} \mathrm{dm}^{-3}$ & 18,7 & 17,6 & 18,2 & 11,6 \\
$\mathrm{~K}^{+}$ & $\mathrm{mg} \mathrm{dm}^{-3}$ & 0,1 & 0,1 & 0,9 & 0,4 \\
$\mathrm{PO}_{4}{ }^{3-}$ & $\mathrm{mg} \mathrm{dm}^{-3}$ & 5,2 & 5,1 & 4,5 & 1,9 \\
\hline
\end{tabular}

Em seguida, estes valores foram convertidos em perdas de solo em função do total escoado a cada evento. Para calcular as perdas de íons, os valores de perdas de solo foram convertidos, tendo como base o teor dos mesmos presentes no solo e constatados nas análises de cada ano (Tabela1). As análises dos íons solúveis e trocáveis foram realizadas no Laboratório de Análise de Água, Solo e Tecidos Vegetais - LABAS do Instituto Federal de Educação, Campus Iguatu-CE, conforme a metodologia descrita pela EMBRAPA (2011).

Após a quantificação das perdas de íons, os teores foram convertidos para nutrientes e passados para fórmulas comerciais dos fertilizantes mais utilizadas. $\mathrm{O}$ $\mathrm{PO}_{4}{ }^{3-}$ foi convertido para superfosfato triplo (SFT) que contém $18 \%$ de $\mathrm{P}_{2} \mathrm{O}_{5}$; o $\mathrm{K}^{+}$para $\mathrm{KCl}$ com $60 \%$ de $\mathrm{K}_{2} \mathrm{O}$ e a soma " $\mathrm{Ca}^{2+}+\mathrm{Mg}^{2+\text { ", }}$ para calcário dolomítico com 38\% de $\mathrm{CaO}$ e MgO. Em seguida os corretivos e fertilizantes foram transformados em quilograma por hectare $\left(\mathrm{kg} \mathrm{ha}^{-1}\right)$ e calculados os valores financeiros das perdas totais de nutrientes em $\mathrm{kg} \mathrm{ha}^{-1} \mathrm{ano}^{-1}$ em reais (R\$) e convertidos para o dólar (US\$) utilizando a cotação de US\$ 3,5774 do dia 30 de maio 2016. Para os cálculos financeiros, foram adotados os valores dos adubos utilizando os preços médios mensais pagos pela agricultura cotados pelo Instituto de Economia Agrícola - IEA na data de 30 de maio 2016 (IEA, 2016).

\section{RESULTADOS E DISCUSSÃO}

Os totais precipitados para os anos 2013 e 2014 foram de 630,75 e 742,89 mm, respectivamente, para a estação chuvosa de cada ano (janeiro a junho) (Figura 3), ficando com precipitação média por eventos inferior $30 \mathrm{~mm}$ e $75 \%$ dos eventos não ultrapassaram $40 \mathrm{~mm}$ de precipitação. Esses valores notadamente baixos influenciaram significativamente na redução dos processos erosivos. 

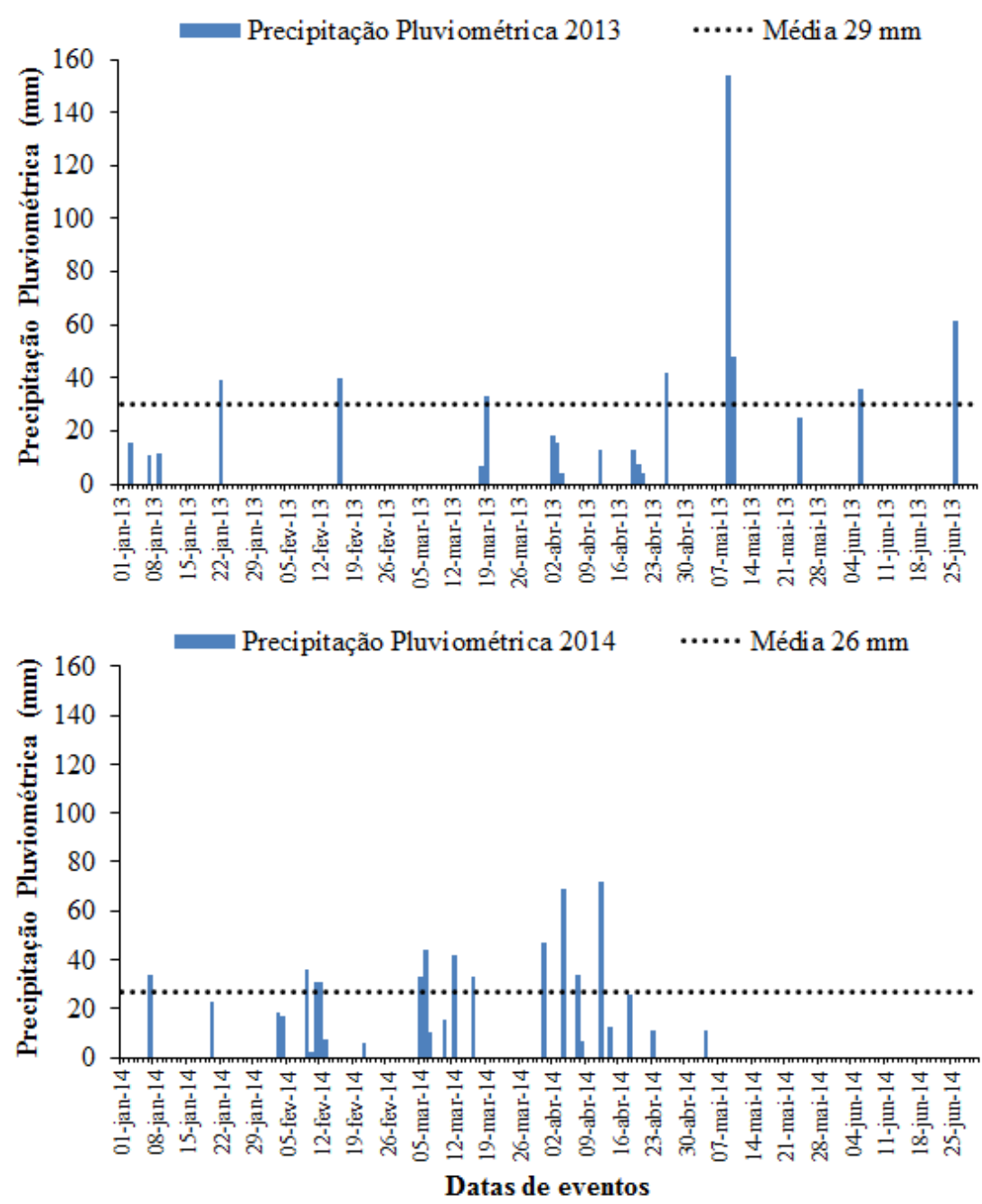

Figura 3 - Precipitação e média pluviométrica nos períodos de estudo: (a) 2013 e (b) 2014.

A maior chuva do período ocorreu no dia 09 de maio de 2013 (154 mm), representando $25,7 \%$ do volume total precipitado na estação chuvosa a daquele ano. A segunda maior chuva do período de estudo ocorreu em 12 de abril de 2014 (72 mm). Altas precipitações são normalmente registradas na região semiárida em abril, quando as intensidades atingem valores superiores a $30 \mathrm{~mm} \mathrm{~h}^{-1}$, o que pode ser considerado crítico para os processos erosivos (RODRIGUES et al., 2013). Valores similares ao da área em estudo foram verificados por
Santos et al. (2007) na região semiárida do estado da Paraíba.

Quando se compara perdas de água para o período de maior precipitação (Tabela 2), verifica-se reduções de até $10,7 \%$ na parcela DQP no mês de maio de 2013 e 46,7\% no mês de abril de 2014 em relação ao solo sem vegetação (parcela DQSV), a baixa redução observada no ano de 2013 se justifica pela baixa intensidade de precipitação ocorrida anteriormente a essa data o que confirma a eficiência deste sistema de manejo na redução das perdas de água e solo.

Tabela 2 - Perdas de água e solo por erosão hídrica em três parcelas de erosão com diferentes usos do solo para os anos 2013 e 2014 na área de estudo em Iguatu, Ceará, Brasil.

\begin{tabular}{ccccccccc}
\multirow{2}{*}{ Ano } & \multirow{2}{*}{ Meses } & \multirow{2}{*}{ Precipitação $(\mathrm{mm})$} & \multicolumn{3}{c}{ Perda de água $(\mathrm{mm})$} & \multicolumn{3}{c}{ Perda de solo $\left(\mathrm{kg} \mathrm{ha}^{-1}\right)$} \\
& & & CC & DQP & DQSV & CC & DQP & DQSV \\
\hline \multirow{2}{*}{2013} & \multirow{2}{*}{ Janeiro } & 78,6 & 0,0 & 0,0 & 17,1 & 0,0 & 0,0 & 863,3 \\
& Fevereiro & 46,3 & 0,0 & 0,0 & 21,2 & 0,0 & 0,0 & $1.037,7$ \\
\hline
\end{tabular}




\begin{tabular}{|c|c|c|c|c|c|c|c|c|}
\hline & Março & 64,8 & 0,1 & 0,0 & 41,9 & 0,0 & 0,0 & $1.064,1$ \\
\hline & Abril & 124,4 & 0,0 & 0,0 & 63,6 & 0,0 & 0,1 & $2.427,2$ \\
\hline & Maio & 229,3 & 19,8 & 85,8 & 96,1 & 28,2 & 81,5 & 4.366,1 \\
\hline & Junho & 87,3 & 0,0 & 0,0 & 70,5 & 0,0 & 0,0 & $2.734,5$ \\
\hline & Total & 630,75 & 19,9 & 85,8 & 310,4 & 28,2 & 81,6 & $12.493,0$ \\
\hline \multirow{7}{*}{2014} & Janeiro & 50,3 & 0,0 & 0,0 & 18,3 & 0,0 & 0,0 & 392,5 \\
\hline & Fevereiro & 148,6 & 0,0 & 14,9 & 49,4 & 0,0 & 21,6 & $1.165,4$ \\
\hline & Março & 218,2 & 0,5 & 8,3 & 135,8 & 1,2 & 36,1 & $3.586,0$ \\
\hline & Abril & 230,6 & 15,5 & 87,7 & 164,8 & 5,8 & 136,0 & $8.590,4$ \\
\hline & Maio & 69,0 & 0,0 & 0,0 & 11,3 & 0,0 & 0,0 & 85,4 \\
\hline & Junho & 26,0 & 0,0 & 0,0 & 0,0 & 0,0 & 0,0 & 0,0 \\
\hline & Total & 742,9 & 16,0 & 110,9 & 379,6 & 7,0 & 193,7 & $13.819,7$ \\
\hline
\end{tabular}

$\mathrm{Na}$ parcela com solo sem vegetação (DQSV), ocorreram as maiores perdas de solo e água, apresentando nos anos de 2013 e 2014 perdas de solo de 12.493 e $13.819,7 \mathrm{~kg} \mathrm{ha}^{-1}$, respectivamente (Tabela 2). A parcela de erosão sem cobertura traduz os efeitos diretos da erosividade da chuva na desagregação e transporte das partículas de solo sem o efeito protetor da vegetação. Nessa condição de total falta de vegetação, eventos de alto poder erosivo são responsáveis pelas maiores perdas de solo. Estudo realizado na mesma bacia por Araujo et al. (2016), também verificaram eficiência da cobertura vegetal sobre o solo em relação aos processos erosivos.

As irregularidades na distribuição dos eventos de chuva, com ocorrência de veranicos e redução da umidade do solo (Figura 3) minimizaram as perdas de água e aliadas ao manejo aplicado com cobertura vegetal rasteira de capim forrageiro. Desta forma proporcionou baixas perdas de solo, com valores de 81,6 e 193,7 $\mathrm{kg} \mathrm{ha}^{-1}$ para os anos de 2013 e 2014, respectivamente. PALÁCIO et al, (2012) estudando as respostas hidrossedimentológicas de microbacias no semiárido, na região centro sul do Ceará, observaram que a cobertura vegetal apresentou expressiva redução no controle do processo erosivo. Assim, a presença da cobertura vegetal no tratamento DQP contribuiu para redução de $99 \%$ nas perdas de sedimento em relação à parcela sem vegetação (DQSV), o que também foi relatado por Guan-Hua et al. (2011).
Embora a parcela com capim tenha apresentado redução nas perdas de solo, observa-se que a mesma (DQP) apresentou perdas de solo 3 vezes maiores que a parcela com Caatinga conservada (CC) em 2013 e 27 vezes em 2014. Este comportamento mostra que a precipitação e o manejo aplicado apresentaram grande influência sobre as perdas de solo em relação ao sistema conservado. Alterações ambientais como a redução da cobertura vegetal geram grandes impactos negativos sobre o solo (OLIVEIRA et al., 2012; LIU et al., 2012).

Observa-se, também, que a parcela DQP, é mais eficiente em reduzir as perdas de solo que as perdas de água (Tabela 2), pois quando se compara o total de escoamento superficial no período de estudo entre as parcelas DQSV e DQP, as perdas de água foram $71 \%$ menores na parcela DQP. Cantón et al. (2011) pesquisando escoamento e erosão em escala de parcelas e microbacias verificaram que a presença ou ausência de vegetação é considerada o principal fator determinante das perdas de água e solo.

Do ponto de vista econômico, analisando os custos financeiros de reposição de nutrientes com formas de fertilizantes SFT, $\mathrm{KCl}\left(\mathrm{PO}_{4}{ }^{3-}, \mathrm{K}^{+}\right)$e corretivo Calcário $(\mathrm{Ca}+$ $\mathrm{Mg}$ ), observa-se que para os tratamentos em estudo (Caatinga conservada - CC, desmatamento/queima/pastagem - DQP e desmatamento/queima/sem vegetação DQSV) as perdas financeiras médias corresponderam a 1,94 R\$ ou US\$ 0,54, 10,29 
R\$ ou US\$ 2,88 e 118,96 R\$ ou US\$ 33,25 ha hano $^{-1}$, respectivamente (Tabela 3).

Tabela 3 - Quantidades totais de perdas de fertilizantes e financeiras em parcelas de erosão no semiárido para os anos de 2013 e 2014.

\begin{tabular}{|c|c|c|c|c|c|c|}
\hline \multirow{2}{*}{$\begin{array}{c}\text { Fertilizante } \\
\text { comercial }\end{array}$} & \multicolumn{2}{|c|}{$\begin{array}{l}\text { Perdas equivalentes } \\
\qquad\left(\mathrm{kg} \mathrm{ha}^{-1} \mathrm{ano}^{-1}\right)\end{array}$} & \multirow{2}{*}{$\begin{array}{c}\begin{array}{c}\text { Preço do } \\
\text { fertilizante }\end{array} \\
\left(\mathrm{R} \$ \mathrm{~kg}^{-1}\right) \\
\end{array}$} & \multicolumn{2}{|c|}{$\begin{array}{l}\text { Equivalência } \\
\left(\mathrm{R} \$ \text { ha }^{-1} \mathrm{ano}^{-1}\right)\end{array}$} & \multirow{2}{*}{$\begin{array}{l}\text { Média do custo } \\
\text { financeiro da erosão } \\
\text { hídrica (2013-2014) }\end{array}$} \\
\hline & 2013 & 2014 & & 2013 & 2014 & \\
\hline \multicolumn{7}{|c|}{ Manejo Caatinga Conservada - CC } \\
\hline SFT (P) & 0,28 & 0,33 & 1,93 & 0,54 & 0,64 & 0,59 \\
\hline $\mathrm{KCl}(\mathrm{K})$ & 0,62 & 0,40 & 2,00 & 1,24 & 0,80 & 1,02 \\
\hline Calcário (Ca + Mg) & 4,80 & 2,63 & 0,09 & 0,43 & 0,24 & 0,33 \\
\hline & \multicolumn{3}{|c|}{ Perda total (R\$) } & 2,21 & 1,67 & 1,94 \\
\hline & \multicolumn{3}{|c|}{ Conversão para dólar (US\$) } & 0,62 & 0,47 & 0,54 \\
\hline \multicolumn{7}{|c|}{ Manejo Desmatamento/Queima/Pastagem - DQP } \\
\hline SFT (P) & 4,20 & 2,03 & 1,93 & 8,11 & 3,92 & 6,01 \\
\hline $\mathrm{KCl}(\mathrm{K})$ & 2,10 & 0,71 & 2,00 & 4,20 & 1,42 & 2,81 \\
\hline \multirow[t]{3}{*}{ Calcário (Ca + Mg) } & 25,37 & 7,17 & 0,09 & 2,28 & 0,65 & 1,46 \\
\hline & \multicolumn{3}{|c|}{ Perda total (R\$) } & 14,59 & 5,98 & 10,29 \\
\hline & \multicolumn{3}{|c|}{ Conversão para dólar (US\$) } & 4,08 & 1,67 & 2,88 \\
\hline \multicolumn{7}{|c|}{ Manejo Desmatamento/Queima/Sem Vegetação - DQSV } \\
\hline SFT (P) & 6,91 & 29,87 & 1,93 & 13,34 & 57,65 & 35,49 \\
\hline $\mathrm{KCl}(\mathrm{K})$ & 12,60 & 40,62 & 2,00 & 25,20 & 81,24 & 53,22 \\
\hline \multirow[t]{3}{*}{ Calcário (Ca + Mg) } & 322,44 & 349,70 & 0,09 & 29,02 & 31,47 & 30,25 \\
\hline & \multicolumn{3}{|c|}{ Perda total (R\$) } & 67,56 & 170,36 & 118,96 \\
\hline & \multicolumn{3}{|c|}{ Conversão para dólar (US\$) } & 18,88 & 47,62 & 33,25 \\
\hline
\end{tabular}

Custos dentro das mesmas ordens de grandeza da tabela 3 foram encontrados por Carvalho et al. (2014). Dentre as substâncias que mais contribuíram com o montante das perdas, destaca-se o corretivo calcário $(\mathrm{Ca}+$ $\mathrm{Mg}$ ) e o fertilizante potássio, esse fato está relacionado a alta concentração desses nutrientes proveniente da geologia da região do estudo. encontrado na área de estudo.

O tratamento CC foi o que apresentou menor perda financeira, visto que a floresta tem grande influência na redução da energia cinética disponível para a desagregação e transporte de partículas de solo e favorece a infiltração, o que implica em redução das perdas de água e solo e consequentemente dos nutrientes agregados aos mesmos. Para o tratamento DQP o acréscimo das perdas financeiras em relação ao tratamento CC se justifica pela substituição da cobertura vegetal nativa por pastagem de capim (Andropogon gayanus Kunt) que proporcionou menor retenção da água de escoamento e maiores perdas de água, solo e nutrientes. Segundo Casermeiro et al.; (2004), a fisionomia das plantas (extratos herbáceo ou arbóreo) provocam diferentes valores de interceptação da chuva.

No tratamento DQSV as elevadas perdas de calcário, $\mathrm{KCl}$ e SFT estão relacionadas a ausência da cobertura vegetal que reduz a rugosidade da superfície e favorece o escoamento superficial proporcionando maiores remoções dos nutrientes. Para os anos de 2013 e 2014, no manejo DQSV, as perdas financeiras atingiram $67,56 \mathrm{R} \$$ ou US\$ $18,88 \mathrm{ha}^{-1} \mathrm{ano}^{-1} \mathrm{e}$ $170.36 \mathrm{R} \$$ ou US\$ 47,62 ha $^{-1} \mathrm{ano}^{-1}$, respectivamente. Observa-se que para o ano de 2014 ocorreram acréscimos de 
aproximadamente $44 \%$ no total das perdas financeiras, quando comparado com o ano de 2013. Este incremento se deve principalmente ao maior volume de precipitação em 2014, o que favoreceu as perdas em virtude da ausência da cobertura vegetal (GARCIAESTRINGANA et al., 2013).

Para o tratamento na parcela DQP, as perdas totais de SFT, KCl e Calcário foram aproximadamente 29 vezes menores que as perdas financeiras observadas no manejo DQSV, estando, estes acréscimos, atribuídos à presença da cobertura vegetal que funciona como interceptador da chuva, o que favorece a infiltração. Comportamento semelhante foi observado por Thomazini et al. (2012) em estudo realizado no sul do estado do Espíritto Santo, o mesmo observou expressivo aumento nas perdas de solo, água e nutrientes em sistema convencional sem cobertura vegetal comparado com sistema conservacionista.

$\mathrm{Na}$ parcela DQP as perdas fósforo na forma de SFT considerando a equivalência (R\$ ha ${ }^{1}$ ano $^{-1}$ ), apresentou 93\% de acréscimo em relação ao tratamento CC. Estas perdas, além dos prejuízos econômicos, podem contribuir com os processos de contaminação dos reservatórios hídricos. As perdas de SFT encontradas neste estudo são condizentes com as obtidos por Bertol et al. (2007); Bertol et al. (2011) e Gilles et al. (2009).

Para o ano de 2014, embora o volume de precipitação tenha sido maior do que o verificado em 2013 (Figura 3), observa-se que foi registrado as menores perdas de nutrientes na forma de SFT, $\mathrm{KCl}$ e Calcário para os tratamentos DQP e CC. Segundo Cantón et al.; (2011), esse fato pode ser explicado pela maior concentração de eventos pluviométricos no início da estação chuvosa, concorrendo para melhor desenvolvimento da vegetação herbácea nos dois usos do solo, conferindo maior cobertura vegetal e menores perdas.

A partir do comportamento das perdas em kg ha-1 $\mathrm{ano}^{-1}$, para os dois anos de estudo nos tratamentos CC e DQSV observa-se que as perdas ocorreram na seguinte ordem: Calcário $(\mathrm{Ca}+\mathrm{Mg})>\mathrm{KCl}(\mathrm{K})>\mathrm{SFT}(\mathrm{P})$. Esse fato provavelmente está relacionado a alta concentração do $\mathrm{Ca}, \mathrm{Mg}$ e $\mathrm{K}$, o que facilita as perdas por sólidos transportados e a baixa concentração do fósforo $(\mathrm{P})$ no solo. No tratamento DQP o SFT (P) observaram perdas mais elevadas de SFT $(\mathrm{P})$ que potássio $(\mathrm{KCl})$ nos dois anos de estudo, o que pode ser atribuído a reposição do fosforo através das cinzas, aumentando relativamente as perdas do mesmo. Comportamento do fósforo foi relatado por Klein et al. (2012).

\section{CONCLUSÕES}

- O Desmatamento/Queima e sem Vegetação-DQSV proporciona as maiores perdas de água, solo e íons correspondendo a custos financeiros para reposição nutricional do solo 60 vezes maior que as perdas da Caatinga Conservada-CC;

- A cobertura vegetal foi eficiente na redução das perdas de água e solo, sendo as menores perdas registradas na Caatinga Conservada-CC seguida dos usos de Desmatamento/Queima e Pastagem-DQP e do Desmatamento/Queima e Sem Vegetação-DQSV;

- As menores perdas por erosão foram proporcionadas pela parcela de Caatinga Concervada com R\$ 1,94 ou US\$ 0,5 ha $\mathrm{ano}^{-1}$ enquantto o manejo (DQSV) apresentou as maiores perdas financeiras R\$ 118,96 ou US\$ 33,25 ha ano ${ }^{-1}$.

\section{AGRADECIMENTOS}

Os autores agradecem à Fundação Cearense de Apoio ao Desenvolvimento Cientifico e Tecnológico (FUNCAP) pelo apoio financeiro à pesquisa e bolsa de produtividade (BPI) da segunda autora e ao Conselho Nacional de Desenvolvimento Científico e Tecnológico (CNPq) pelo apoio financeiro à pesquisa.

\section{REFERÊNCIAS}

AGRIEMPO - Sistema de moniorameno agrometeorológico, Dados meteorológico Iguatu (INMET), dados históricos. Disponível 
em:

http://www.agritempo.gov.br/agroclima/sumá rio. Acesso em: 16 de maio de 2013.

ANDRADE, E. C. R.; SALIN, T. C.; LINARES, C. R. A.; SAMPAIO, R. L. M. Consórcios agroflorestais como garantia da biodiversidade e sustentabilidade ambiental para a agricultura familiar: o caso do sítio Nova Canaã. Revista Brasileira de Agroecologia, v. 4, n. 2, p. 2851-2854, 2009.

ARAUJO, Y. R.; SOUZA, C. A.; ARAÚJO NETO, J. R.; RIBEIRO FILHO, J. C.; LIMA, J. W. C. Perda de nutriente e custo da erosão em microbacia no semiárido brasileiro. Revista geonorte, Edição Especial 5, v. 7, n. 26, p. 206-219. 2016.

BARBOSA, F. T.; BERTOL, I.; LUCIANO, R. V.; GONZÁLEZ, A. P.; VÁZQUEZ, E. V. Teor de nitrogênio solúvel na água de erosão hídrica em cultura de aveia e ervilhaca em três formas de semeadura. Revista brasileira de ciência do solo, v. 33, p. 439 - 446, 2009.

BERTOL, I.; COGO, N. P.; SCHICK, J.; GUDAGNIN, J. C.; AMARAL, A. J. Aspectos financeiros relacionados às perdas de nutrientes por erosão hídrica em diferentes sistemas de manejo do solo. Revista Brasileira de Ciência do Solo, v. 31, n. 1, p. 133-142, 2007.

BERTOL, I.; GOBBI, E.; BARBOSA, F. T.; PAZ-FERREIRA, J.; GEBLER, L.; RAMOS, J. C.; WERNER, R. S. Erosão hídrica em campo nativo sob diversos manejos: perdas de água e solo e de fósforo, potássio e amônio na água de enxurrada. Revista Brasileira de Ciências do Solo, v. 35, p. 1421-1430, 2011.

CANTÓN, Y.; SOLÉ-BENET, A.; DE VENTE, J.; BOIX-FAYOS, C.; CALVOCASES, A.; ASENSIO, C.; PUIGDEFÁBREGAS, J. A review of runoff generation and soil erosion across scales in semiarid south-eastern Spain. Journal of Arid Environments, v. 75, n. 12, p. 12541261, 2011.
CASERMEIRO, M. A.; Molina, J. A.; Caravaca,M. T. D. L.; Costa, J. H.; Massanet, M. I. H.; Moreno, P. S. Influence of scrubs on runoff and sediment loss in soils of Mediterranean climate. Catena. v. 57, p. 91107, 2004.

CAVALCANTI, N. B.; L. T. L. BRITO. Perda de solo e água em diferentes sistemas de cultivo na caatinga. Engenharia Ambiental, Espírito Santo do Pinhal. v. 9, n. 2, p. 105-118, 2012.

CARDOSO, D. P.; SILVA, M. L. N.; CARVALHO, G. J.; FREITAS, D. A. F.; AVANZI, J. Plantas de cobertura no controle das perdas de solo, água e nutrientes por erosão hídrica. Revista Brasileira de Engenharia Agrícola e Ambiental, v.16, n.6, p.632-638, 2012.

CARVALHO, F. W. A.; MADUREIRA, L. M. C.; ANDRADE, E. M.; PALÁCIO, H. A. Q.; VIEIRA, H. Determinação do custo econômico da erosão do solo: uma avaliação a partir das formas de uso do solo na região centro-sul do ceará. 20 ${ }^{\mathrm{TM}}$ APDR CONGRESS. Renaissance of the regions of Southern Europe. University of Évora, 2014.

EMBRAPA. Centro Nacional de Pesquisa de Solos. Sistema Brasileiro de Classificação de Solos. 3 ed. Brasília-DF: Embrapa, 2013. $353 \mathrm{p}$.

EMBRAPA - EMPRESA BRASILEIRA DE PESQUISA AGROPECÁRIA - EMBRAPA. Manual de métodos de análises de solo. 2. ed. Rio de Janeiro, 225p. 2011.

GARCIA-ESTRINGUEIRA， P.; ALONSOBLÁZQUEZ, N.; MARQUES, M. J.; BIENES, R.; GONZÁLEZ-ANDRÉS, F.; ALEGRE, J. Use of Mediterranean legume shrubs to control soil erosion and runoff in central Spain. A large-plot assessment under natural rainfall conducted during the stages of shrub establishment and subsequent colonization. Catena, v. 102. p. 3-12, 2013. 
GILLES, L.; COGO, N. P.; ISSANI, C. A.; BAGATINI, T.; PORTELA, J. C. Perdas de água, solo, matéria orgânica e nutriente por erosão hídrica na cultura do milho plantada em área de campo nativo, influenciadas por métodos de preparo do solo e tipos de adubação. Revista Brasileira de Ciências do Solo, v.33, p. 1427-1440, 2009.

GONZALEZ-HIDALGO, J. C.; BATALLA, R. J.; CERDA, A.; A Catchment size and contribution of the jargest daily events to suspended sediment load on the continental scale. Catena, v. 102, p. 40-45, 2013.

GUAN-HUA, Z.; GUO-BIN, L.; GUOLIANG, W.; YU-XIA, W. Effects of vegetation cover and rainfall intensity on sediment-bound nutrient loss, size composition and volume fractal dimension of sediment particles. Pedosphere, v. 21, n. 5, p. 676-684, 2011.

IEA - Instituto de Economia Agrícola. Preços Médios Mensais Pagos pela Agricultura. Disponível em: http://ciagri.iea.sp.gov.br/nia1/Precos_Medios .aspx?cod_sis=5. Acesso em: 06 de junho de 2016.

KLEIN, C.; AGNE, S. A. A. Fósforo: de nutriente à poluente. Revista Eletrônica em Gestão, Educação e Tecnologia Ambiental, v. 8, n. 8, p. 1713-1721, 2012.

LIU, R.; WEIWANG, J.; SHI, J.; CHEN, Y.; SUN, C.; ZHANG, P.; SHEN, Z. Runoff characteristics and nutrient loss mechanism from plain farmland under simulated rainfall conditions. Science of the Total Environment, v. 468, n. 469, p. 1069-1077, 2014.

LIU, Y.; TAO, Y.; WAN, K. Y.; ZHANG, G. S.; LIU, D. B.; XIONG, G. Y.; CHEN, F. Runoff and nutrient losses in citrus orchards on sloping land subjected to different surface mulching practices in the Danjiangkou Reservoir area of China. Agricultural Water Management, v. 110, p. 34- 40, 2012.
MORUZZI, R. B.; CUNHA, C. M. L; BRAGA, R.A questão do escoamento superficial em áreas degradadas por processos erosivos lineares: a importância de uma estratégia de análise. Engenharia Ambiental, Espírito Santo do Pinhal. v. 6, n. 2, p. 073088, 2009.

OLIVEIRA， J. G. R.; REALISCH, R.; GUIMARÃES, M. F.; BARBOSA, G. M. C.; TAVARES FILHO, J. Erosão no plantio direto: perda de solo, água e nutrientes. Boletim de geografia de Maringá, v. 30, n. 3, p. 91-98, 2012.

PALÁCIO, H. A. Q.; SILVA FILHO, J. A.; ANDRADE, E. M.; SANTOS, J. C. N.; BRASIL, P. P. Uso da terra e resposta hidrossedimentológica de Microbacia no semiárido. Revista Agro@mbiente On-line, v. 6, n. 3, p. 187-194, 2012.

PALÁCIO, H. A. Q.; ANDRADE, E. M.; SANTOS, J. C. N.; ARAÚJO NETO, J. R.; BRASIL, P. P. Energy evaluation of semi-arid watersheds under different management strategies. Transactions of the ASABE, v. 56, p.1-7, 2013.

PEREIRA, P. S. VEIGA, B. V.; DZIEDZIC, M. Avaliação da influência do fósforo e do nitrogênio no processo de eutrofização de grandes reservatórios estudo de caso: Usina Hidrelétrica Foz do Areia Revista Brasileira de Recursos Hídricos, v.18, n.1, p. 43-52, 2013.

PIMENTEL, D.; HARVEY, C.; RESOSUDARMO, P.; SINCLAIR, K.; KURZ, D.; MCNAIR, D.; CRIST, S.; SHPRITZ, L.; FITTON, L.; SAFFOURI, R.; BLAIR, R.. Environmental and economic costs of soil erosion and conservation benefits. Science, New Series, v. 267, n. 5201, p. 1117-1123, 1995.

RODRIGUES, J. O.; ANDRADE, E. M.; PALÁCIO, H. A. Q.; MENDONÇA, L. A. R.; SANTOS, J. C. N. Produção de sedimentos em microbacias hidrográficas semiáridas 
sobre manejos diferenciados. Revista

Ciência Agronômica, v. 44, n. 3, p. 488-498, 2013.

SANTOS, C. A. G.; SILVA, R. M.; SRINIVASAN, V. Análise das perdas de água e solo em diferentes coberturas superficiais no semiárido da Paraíba. Revista OKARA: Geografia em Debate, v. 1, n. 1, p. 16-32, 2007.
SILVA, F. C. Manual de análises químicas de solos, plantas e fertilizantes, EMBRAPA. $2^{\mathbf{a}}$ edição, Brasília, DF: 2009. 627 p.

THOMAZINI, A.; AZEVEDO, H. C. A.; MENDONÇA, E. S. Perdas de solo, água e nutrientes em sistemas conservacionistas e convencionais de café no sul do estado do Espírito Santo. Revista Brasileira de Agroecologia, v. 7, n. 2, p. 150-159, 2012. 